$\begin{gathered}\text { Journal of Business Management and } \\ \text { Economic Research }\end{gathered} \mid$

\title{
Humble Leadership and Employee Creativity: The Mediating Role of Knowledge Hiding
}

\section{Zhen Liu, Wenbo Liu}

Corresponding Author: Wenbo Liu, School of Management, Shanghai University, Shangda Avenue, Baoshan District, Shanghai, China.

tianweijun55@163.com

\begin{abstract}
Based on the perspective of resource conservation theory, this paper adopts the questionnaire survey method and takes 345 enterprise employees as samples to discuss the impact of humble leadership on employee creativity and how the perceived organizational support has a moderating effect on the relationship between humble leadership and employee creativity. The results show that humble leadership has a positive influence on employee creativity, and this relationship is mediated by knowledge hiding. Perceived organizational support positively moderates the relationship between humble leadership and employee creativity.
\end{abstract}

Keywords: Humble leadership; employee creativity; perceived organizational support; knowledge hiding

\section{1. introduction}

With the rapid development of social economy and the science and technology continue to update iteration, innovation has gradually become the internal driving force for the development and progress of enterprises. In order to adapt to the changing environment and maintain their competitive advantages, enterprises can only rely on innovation to stand out in the increasingly fierce competitive environment. However, the innovation of enterprises cannot be separated from the creativity of employees. Research shows that the employee creativity is 
the starting point of enterprise innovation and the survival basis of improving enterprise performance (Zhou S J, 2003; Gong Y, Huang J C \& Farh J L, 2009). How to improve the employee creativity has become an urgent problem for enterprises.

There are many factors affecting employee creativity, the leaders who are in close contact with their employees have a profound influence on employees' words and deeds. At present, many scholars explain the internal influence mechanism of employee creativity from the perspective of leadership and find that different leadership styles have different influences on employee creativity (Qiufeng Huang \& Ningyu Tang 2016). As a new "bottom-to-top" leadership style, humble leadership is highly valued by scholars. The cultural characteristics of eastern and western organizations are different to some extent, which also leads to the different reactions of employees to humble leadership in different organizations. Therefore, humble leadership may have different influences on the eastern and western organizations. Especially in the context of traditional Chinese culture, the study of humble leadership has become crucial. How humble leadership affects employee creativity has become a hot topic in the field of organization and management.

In the era of iterative innovation, enterprise competitiveness has shifted from traditional resources (such as land, machinery and equipment, etc.) to knowledge resources, as the carrier of knowledge resources, employees may not willing to share their resources, which leads to the ineffective use of resources in the organization. Some scholars have studied the relationship between humble leadership and employee creativity from the perspectives of social cognition, power distance and personality traits (Jinlian Luo et al., 2016; Yunna Luo \& Gaosheng Yang, 2019; Yanzi Wang et al., 2016), but ignored the impact of knowledge hiding on employee creativity from the perspective of resource conservation theory. Knowledge hiding is the behavior of an individual in an organization to deliberately hide or conceal knowledge in the face of other people's knowledge requests (Connelly C E et al., 2012). At present, there are many papers research on the antecedent variables of knowledge hiding, but few empirical studies on the outcome variables of knowledge hiding. The study found that in order to make the most of 
their knowledge resources, employees can simultaneously improve knowledge sharing and reduce knowledge hiding (Kang S W, 2014), and knowledge sharing can promote employee creativity (Yunna Luo \& Gaosheng Yang, 2019), so the relationship between knowledge hiding and employee creativity is worth further discussion.

Based on the theory of conservation resource theory, on the basis of literature review, this paper using the theory of psychology, organizational behavior and other fields to build the conceptual model of the role of humble leadership on employee creativity, knowledge hiding as the mediation variable, perceived organizational support as the moderator variable, using hierarchical regression analysis and other empirical methods for hypothesis test, delves into the humble leadership impact on employee creativity and knowledge hiding in the intermediary role, provide a theoretical basis for enterprises to further improve their innovation ability.

\section{Literature Reviews and Research Hypothesis}

\subsection{Humble Leadership and Employee Creativity}

Humility is the core of humble leadership and it has a long history in China. It can be seen from the Taoist and Confucian cultures that the importance of humility in the development of China's history. For example, the spirit of "Highest excellence as water" advocated by Taoist and the spirit of "One should be fond of learning and not feel ashamed to ask and learn of his inferiors." advocated by Confucianism that both show the humble mentality of being diligent in learning. But now the connotation of humility is more complex than our previous cognition. From the perspective of psychology, humility is not the negation of oneself, but the objective evaluation of oneself. It is known that modesty is the traditional virtue of the Chinese nation, while humility and modesty are similar but not the same. Modesty is an external behavior, while humility is an internal quality. Modest leaders maybe not humble in heart, but humble leaders always show the modest behavior. Owens (2012) pointed out several connotations of humble leadership, such as having the courage to admit their shortcomings, appreciating the strengths and efforts of subordinates, and constantly learning. 
Creativity is the ability to come up with new ideas, and discover and create new things. Employee creativity is an important part of enterprise innovation, but innovation is a behavior with high uncertainty and high risk (Zhang X et al., 2010). The ability of appreciate subordinates and the trait of modest learning of humble leadership will promote the psychological security of employees, and humble leadership can also improve the dedication and self-efficacy of employees (Nielsen R et al., 2010). In addition, humble leaders dare to admit their shortcomings, which can tolerate the shortcomings of subordinates and reduce the psychological pressure and burden of employees in the process of innovation. Besides, the trait of the humble leader that praises the efforts and the advantages of the subordinates will give the employees confidence and motivation to innovate. In the process of employee innovation, the humble leader actively puts forward his own ideas and suggestions so they can provide the employees with a relaxed working atmosphere, thus reducing the obstacles in the process of innovation. Thus:

\section{Hypothesis 1: Humble leadership is positively related to employee creativity.}

\subsection{The Mediating Role of Knowledge Hiding}

Knowledge hiding is the behavior of employees in an enterprise who intentionally hide or conceal knowledge in the face of knowledge requests. It includes three aspects of hiding behaviors: rationalized hiding, playing dumb, and evasive hiding (Connelly C E, 2012). Knowledge hiding is not the opposite of knowledge sharing, nor is it the same as the lack of knowledge sharing (Ford D P, 2008). One of the reasons for the lack of knowledge sharing may be that employees are not clear about the questions that asked by their colleagues so they unable to answer them. Knowledge hiding means that employees know the information that consulted by colleagues, but deliberately conceal it. Resource conservation theory holds that individuals have the motivation to acquire, maintain and protect resources. Therefore, when employees' knowledge information is infringed or employees perceive that the ownership of knowledge will change, they will maintain and protect knowledge resources. As a result, the 
behavior of knowledge hiding will be happened.

Research shows that knowledge is a major component of human resources, and individuals will choose knowledge hiding when they feel that their ownership of knowledge is not fixed or their rights and interests may be infringed (Yiming He,2014). Humble leadership has an inhibitory effect on employees' knowledge hiding (Ling Yuan,2018), and knowledge hiding is not conducive to the exchange of knowledge among members. In addition, when employees choose knowledge hiding, they will lose the trust of others in the organization, resulting in a vicious circle where others are unwilling to share knowledge, and the creativity of knowledge hiders will also decline (Cerne M, 2014). However, new knowledge is the basic condition for new ideas, and employee creativity often requires the integration of different resource information and the identification of their internal relations (Dyne L V, 2002). Therefore, we propose:

Hypothesis 2: Knowledge hiding partially mediates the relationship between humble leadership and employee creativity.

\subsection{Perceived Organizational Support as Moderators}

Perceived organizational support was first proposed by Eisenberger, an American social psychologist. It is a comprehensive subjective perception of the organization by employees, including the evaluation of the employee's work and the focus on the well-being of employees by organization (Eisenberger $\mathrm{R}$ et al., 1986). When employees have a high sense of perceived organizational support, the incentive from the organization will urge employees to perform better in work (Eisenberger R et al., 1986). Research has shown that perceived organizational support has a positive role in promoting employee satisfaction and corporate performance (Kraimer M L \& Wayne S J, 2004), and when employees feel the support from the organization, they would to strengthen their commitment to the organization (Jihua Lu et al., 2013), which is good for generating innovative behavior.

Social exchange theory emphasizes that there is an element of exchange in the relationship between people. In social exchange, people are willing to give positive feedback to those who 
have made positive behaviors towards them, as the same in organization. When the organization provides more support to employees, the harvest and preferential treatment from the external environment make employees more willing to pay and create in the work. The perceived organizational support can be regarded as a kind of resource from the organization, which may alleviate the pressure that generated in the process of individual entrepreneurship. When employees perceive the support of the organization, they will stimulate their work vitality and enthusiasm, so they are more willing to make beneficial behaviors to the organization. Hence, we propose our final hypothesis:

Hypothesis 3: Perceived organizational support positively moderates the relationship between humble leadership and employee.

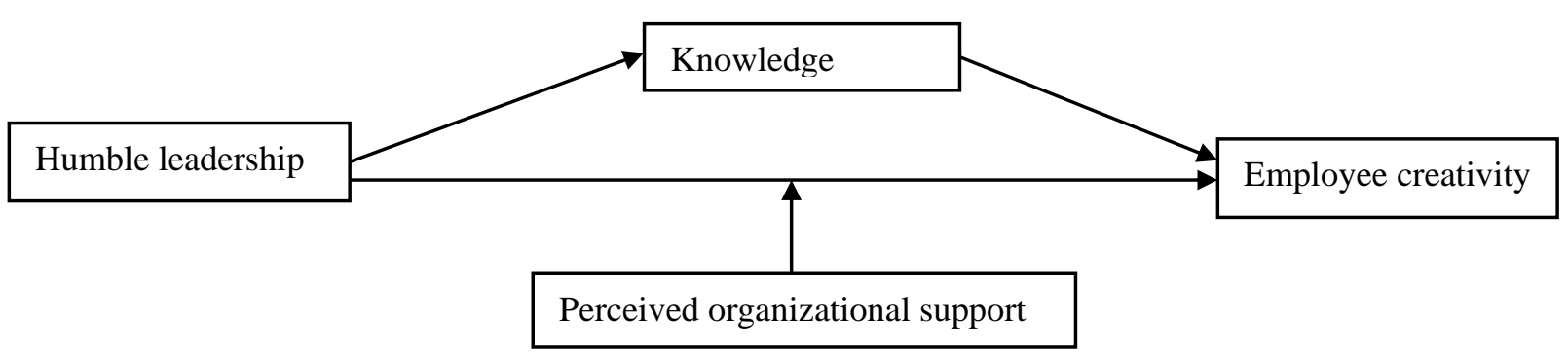

Figure1. The conceptual model of the study

\section{Research Methods}

\subsection{Research Sample}

This study mainly selects the enterprise employees in Shandong, Chongqing, Shanghai, Henan and Hebei as samples, and adopts the form of online survey, 380 questionnaires were distributed, of which 356 were recovered, the recovery rate was $93.68 \%$. Eleven unqualified questionnaires were removed, and 345 valid questionnaires were left, with an effective recovery rate of $90.79 \%$. Among the subjects, female employees account for $55.35 \%$ and male employees 44.64\%. Employees under 25 years old account for $46.09 \%$, employees from 26 to 30 years old account for $29.57 \%$, employees from 31 to 35 years old account for $15.07 \%$, employees from 36 to 
40 years old account for $6.38 \%$, and employees over 40 years old account for $2.9 \%$. The proportion of employees with high school education or below is $5.22 \%$, that of junior college education is $22.9 \%$, that of bachelor degree is $52.75 \%$, and that of master degree or above is $19.13 \%$. In terms of working years, employees with less than one year account for $34.78 \%$, those with 1-3 years account for $31.3 \%$, those with 4-6 years account for $20 \%$, those with $7-10$ years account for 9.28\%, and those with more than 10 years account for $4.64 \%$. Employees of state-owned enterprises accounted for 15.65 percent, private enterprises 39.71 percent, foreign-funded enterprises 11.88 percent, Sino-foreign joint venture 3.77 percent, public institutions 13.91 percent, and other enterprises 15.07 percent.

\subsection{Variable Measurement}

In order to ensure the effectiveness of measurement tools, the scales used in this study are mature scales developed by international top journals. In the process of translation, individual wording would be appropriately modified according to China's national conditions. Likert scale was used for all items in the study, from 1 for complete disagreement to 5 for complete agreement.

Humble leadership. This variable is measured by the scale developed by Owens (2013), which contains 9 items, an example item is "my leader will focus on the strengths of employees". The Cronbach's of the scale in this study was 0.872 .

Knowledge hiding. This was measured using the 12-item identification scale developed by Connelly (2012), which including three dimensions: Playing dumb, such as "pretending do not know even if you know"; Rationalized hiding, such as "my boss won't let me share this information with anyone"; Evasive hiding such as "agreeing to help but providing information that is different from what others want". The final Cronbach's coefficient of the scale was 0.956.

Employee creativity. The scale developed by Zhou (2001) is adopted in this paper. It has a total of 13 items, including "show your creativity in work when given opportunities" and "often find new ways to solve problems". The Cronbach's coefficient of the scale was 0.920 . 
Perceived organizational support. Eisenberger (2002) developed the scale for the measurement of this variable, with a total of 8 items, such as "even if I do my best, my organization will not notice" and "my organization cares about my welfare". The Cronbach's coefficient of this scale is 0.779 .

Control variables. This study takes employees' gender, age, education background, working years and work unit as control variables. These controls were necessary because these variables may affect perceived organizational support, knowledge hiding or employee creativity. The Cronbach's coefficient of the variable is shown in Table 1.

Table 1. The Cronbach's coefficient of the variable

\begin{tabular}{cccccc}
\hline Variable Name & Mean & SD & Cronbach's & Items & Sample quantity \\
\hline Humble leadership & 3.845 & 0.688 & 0.872 & 9 & 345 \\
Knowledge hiding & 2.877 & 1.101 & 0.959 & 12 & 345 \\
Employee creativity & 3.946 & 0.597 & 0.920 & 13 & 345 \\
$\begin{array}{c}\text { Perceived organizational } \\
\text { support }\end{array}$ & 3.633 & 0.621 & 0.779 & 8 & 345 \\
\hline
\end{tabular}

\section{Research Results}

\subsection{Correlation Analysis}

As is shown in table 2, including standard deviation and the correlation coefficient of all variable, it can be found that there is a significant positive correlation between humble leadership and employee creativity $(\mathrm{r}=0.507, \mathrm{P}<0.01)$, the humble leadership and knowledge hiding is significant negative correlation $(\mathrm{r}=-0.142, \mathrm{P}<0.01)$, and knowledge hiding and employee creativity is significantly negative correlation $(\mathrm{r}=-0.179, \mathrm{P}<0.01)$, perceived organizational support and employee creativity significantly positive correlation $(r=0.396, \mathrm{P}<$ 0.01). These results provide a possibility for further verify the hypothesis. 
Table 2. Descriptive statistics and correlations among the study variables $(\mathrm{N}=345)$

\begin{tabular}{|c|c|c|c|c|c|c|c|c|c|c|}
\hline Variables & Mean SD & Gender & Age & Educational & $\begin{array}{c}\text { Working } \\
\text { years }\end{array}$ & Work unit & HL & $\mathrm{EC}$ & $\mathrm{KH}$ & POS \\
\hline Gender & 1.5540 .498 & 1 & & & & & & & & \\
\hline Age & 1.9041 .059 & -.103 & 1 & & & & & & & \\
\hline Educational & 12.8580 .781 & -.014 & $-.206^{* *}$ & 1 & & & & & & \\
\hline $\begin{array}{c}\text { Working } \\
\text { years }\end{array}$ & 2.1771 .144 & $-.167^{* *+}$ & $.811^{* *}$ & $-.352^{* *}$ & 1 & & & & & \\
\hline Work unit & 3.0581 .726 & .078 & $-.148^{* *}$ & $.125^{*}$ & $-.147^{* *}$ & 1 & & & & \\
\hline HL & 3.8450 .688 & -.009 & $.137^{*}$ & -.020 & $.118^{*}$ & -.064 & 1 & & & \\
\hline EC & 3.9460 .597 & -.077 & $.164^{* *}$ & -.092 & $.220^{* *}$ & -.035 & $.507^{* *}$ & 1 & & \\
\hline $\mathrm{KH}$ & 2.8771 .101 & $-.115^{*}$ & $.118^{*}$ & -.077 & .046 & -.054 & $-.142^{* *}$ & $-.179^{* *}$ & 1 & \\
\hline POS & 3.6330 .621 & .027 & $.353^{* * *}$ & $-.149^{* *}$ & $.313^{* *}$ & $-.168^{* *}$ & $.542^{* *}$ & $.396^{* *}$ & $.211^{* *}$ & 1 \\
\hline
\end{tabular}

Note: the results were controlled by gender, age, educational background, working years and work unit. $\mathrm{HL}$ = humble leadership; $\mathrm{KH}$ = knowledge hiding; $\mathrm{EC}=$ employee creativity; POS = perceived organizational support. ${ }^{*} \mathrm{p}<0.05,{ }^{* *} \mathrm{p}<0.01$.

\subsection{Hypothesis Testing}

This paper uses hierarchical regression to analyze the impact of humble leadership on employee creativity and examine the moderating effect of perceived organizational support. In the hierarchical regression analysis, the control variables (gender, age, education background, years of work and work unit) are first entered, then the independent variables (humble leadership) are entered, and finally the interaction terms between humble leadership and organizational support are entered. The results are shown in table 3. 
Table 3. Results of hierarchical regression analysis $(\mathrm{N}=345)$

\begin{tabular}{|c|c|c|c|c|c|c|c|}
\hline \multirow{2}{*}{ Variables } & \multicolumn{5}{|c|}{$\mathrm{EC}$} & \multicolumn{2}{|c|}{$\mathrm{KH}$} \\
\hline & M1 & M2 & M3 & M4 & M5 & M6 & M7 \\
\hline \multicolumn{8}{|l|}{ 1、 controls } \\
\hline Gender & -0.05 & -0.057 & -0.040 & -0.054 & -0.043 & $-0.277^{*}$ & $-0.280^{*}$ \\
\hline Age & -0.02 & -0.051 & -0.067 & -0.082 & -0.076 & $0.280^{* *}$ & $-0.265^{* *}$ \\
\hline Educational & -0.013 & -0.020 & -0.011 & -0.006 & -0.003 & -0.145 & -0.148 \\
\hline working years & $0.123^{*}$ & $0.116^{* *}$ & 0.129 & $0.124^{* *}$ & $0.118^{* *}$ & $-0.025^{*}$ & $0.229^{*}$ \\
\hline Work unit & 0.000 & 0.008 & 0.09 & 0.013 & 0.038 & -0.016 & -0.012 \\
\hline \multicolumn{8}{|l|}{ 2、 Main effect } \\
\hline HL & & $0.429^{* *}$ & $0.416^{* *}$ & $0.360^{* * *}$ & $-0.403^{*}$ & & $-0.209^{*}$ \\
\hline \multicolumn{8}{|c|}{ 3、 Mediating effect } \\
\hline $\mathrm{KH}$ & & & $-0.059^{*}$ & $0.051^{*}$ & $-0.081^{*}$ & & \\
\hline \multicolumn{8}{|c|}{ 4、 Moderating effect } \\
\hline POS & & & & $0.129^{*}$ & -0.685 & & \\
\hline HL x POS & & & & & $0.210^{* *}$ & & \\
\hline $\mathrm{R}^{2}$ & 0.051 & 0.290 & 0.301 & 0.312 & 0.351 & 0.045 & 0.061 \\
\hline$\Delta \mathrm{R}^{2}$ & 0.037 & 0.277 & 0.287 & 0.296 & 0.323 & 0.031 & 0.045 \\
\hline $\mathrm{F}$ 值 & 3.647 & $23.019^{* *}$ & $20.762^{* *}$ & $19.045^{* *}$ & $18.039^{* *}$ & $3.177^{* *}$ & $3.691^{* *}$ \\
\hline
\end{tabular}

Note: $\mathrm{HL}=$ humble leadership; $\mathrm{KH}=$ knowledge hiding; $\mathrm{EC}=$ employee creativity; $\mathrm{POS}=$ perceived organizational support. ${ }^{*} \mathrm{p}<0.05,{ }^{* *} \mathrm{p}<0.01$.

We used the analyses of hierarchical regression to test Hypotheses 1. As can be seen from table 3, humble leadership has a significant positive impact on employee creativity (M2, $\beta=0.429, \mathrm{p}<$ 
0.01), so Hypotheses 1 is supported by data.

Next, we tested mediating effect. Based on the analysis steps designed by Baron (1986), this paper uses the stepwise hierarchical regression method to verify the mediating effect of knowledge hiding between humble leadership and employee creativity. According to the results in table 4 , humble leadership has a significant negative impact on knowledge hiding (M7, $\beta=$ $-0.209, \mathrm{p}<0.05)$. Humble leadership has a significant positive impact on employee creativity (M2, $\beta=0.429, \mathrm{p}<0.01$ ). After the addition of mediating variable (knowledge hiding), humble leadership has a significant impact on employee creativity (M3, $\beta=0.416, \mathrm{p}<0.01$ ), but the regression coefficient becomes smaller, indicating the relationship between humble leadership and employee creativity. Thus, Hypotheses 2 received support.

Finally, we examined Hypothesis 3. It can be seen from table 3 that the interaction between humble leadership and perceived organizational support has a significant positive impact on employee creativity (M5, $\beta=0.210, p<0.01$ ), indicating that the higher of perceived organizational support, the stronger the positive relationship between humble leadership and employee creativity. Therefore, $\mathrm{H} 3$ is supported by data.

In addition, this paper further describes the relationship between the humble leadership and employee creativity with different level of perceived organizational support (as shown in figure 2). The results show that the perceived organizational support enhances the positive influence of humble leadership on employee creativity. In other words, the higher the perceived organizational support, the better the effect of humble leadership on employee creativity. In conclusion, $\mathrm{H} 3$ is valid. 


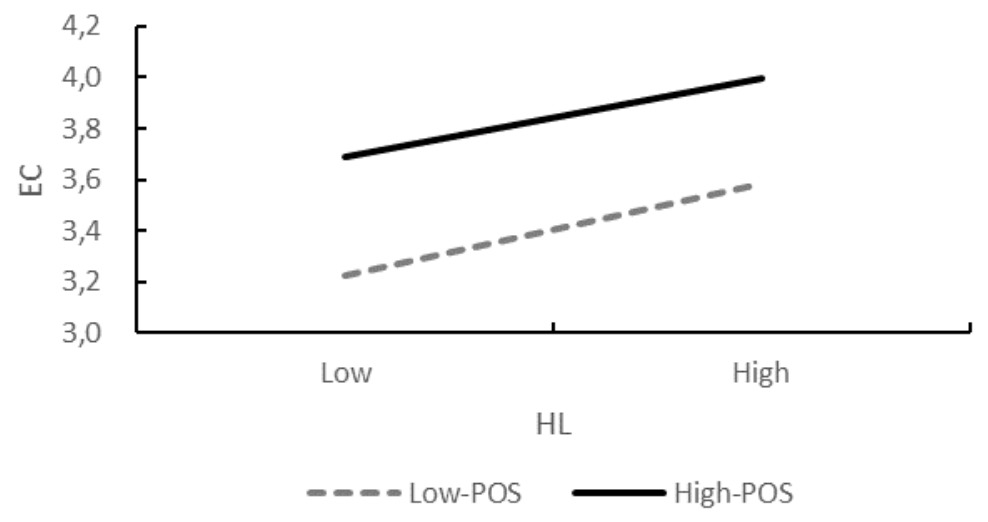

Figure2. Interaction of humble leadership and perceived organizational support on employee creativity

\section{Conclusion}

\subsection{Research Conclusions}

(1) Humble leadership has a significant positive impact on employee creativity. This conclusion is consistent with the existing literature, indicating that humble leadership is generally applicable to Chinese enterprise employees. The trait of humble leadership is an effective precondition to promote the improvement of employee creativity. By being honest about their shortcomings, humble leadership can reduce the pressure of employees in the entrepreneurial process and enable them to face the difficulties in the entrepreneurial process, which is conducive to the improvement of employee creativity. Humble leaders often praise the merits of their subordinates and recognize their efforts, which not only gives employees confidence in the process of starting their own businesses, but also helps them realize their personal value, make them perceive the pleasure and the meaning of innovation, and motivate them to make more efforts. In addition, the learning attitude of the humble leader provides employees with a good learning atmosphere. Humble leadership encourages employees to speak up and be open and inclusive to their opinions, which stimulates the intrinsic motivation of employees to innovate.

(2) Knowledge hiding is partially mediated between humble leadership and employee creativity. Humble leaders' willingness to learn and inclusive and open attitude create a good learning 
atmosphere for employees, thus reducing their knowledge hiding behavior. In addition, humble leaders often praise the advantages of employees, which will enable them to perceive the realization of their own value, motivate them to do more things beneficial to the organization, promote the sharing of knowledge among employees, and thus inhibit their behavior of knowledge hiding. Low knowledge hiding of employees in an enterprise can improve the effective utilization of knowledge resources and the innovation ability of employees.

(3) Perceived organizational support positively moderates the impact of humble leadership on employee creativity. The higher of the perceived organizational support, the more effective the positive impact of humble leadership on employee creativity. As a kind of internal resource, perceived organizational support alleviates the pressure generated by employees in the innovation process. The higher of the perceived organizational support perceived by employees, the stronger the social exchange psychology between employees and the organization, and the individual creativity would more likely to improve. The emotional identity of employees brought by a high perceived organizational support can reduce the pressure that generated in the entrepreneurial process, thus making the mechanism of humble leadership more effective for employee creativity.

\subsection{Theoretical Significance}

First of all, as a new leadership style in recent years, the mechanism of humble leadership on employee creativity has not been deeply empirical analysis and effective verification. Based on the leadership style perspective of employee creativity, this paper constructs and tests a conceptual model between humble leadership and employee creativity. This study verifies the effectiveness of humble leadership in Chinese enterprises, shows the positive impact of humble leadership on the creativity of employees, and reveals the impact of humble leadership on employee creativity. Secondly, this study introduces knowledge hiding as a mediating variable from the perspective of resource conservation theory, which helps explain the influence of humble leadership on employee creativity from multiple perspectives and expands the 
theoretical research on the relationship between leadership and employee creativity. Finally, this paper introduces the perceived organizational support as a moderating variable to explore the effect between humble leadership and employee creativity. The results show that the different degree of perceived organizational support has different results for humble leaders, which enriches the discussion on the mechanism of the humble leadership on employee creativity.

\subsection{Practical Significance}

The research results show that humble leadership has a positive impact on employee creativity, in other words, the more humble the leader is, the higher the employee creativity will be, which provides new ideas for managers to further stimulate employee creativity in the enterprise. Managers should give employees more autonomy and promote employees to share knowledge so as to improve the utilization of resources. Enterprises need to provide a variety of support for employees to further stimulate the creativity of employees so as to improve the innovation ability of the whole organization. The results of this study show that the perceived organizational support, to a certain extent, moderated the relationship between humble leadership and employee creativity. Therefore, organizations should adopt a variety of management measures and management means to improve the perceived organizational support of employees and thus improve the employee creativity.

\subsection{Research Deficiencies and Prospects}

The study in this paper has the following deficiencies: (1) The data used in this study are cross-sectional data, and the causal relationship between variables cannot be further explored. In the future, longitudinal study or experimental method can be selected for verification. (2) Due to limited research conditions, the evaluation of variables in this paper comes from the same subject, and the results may be affected by the common method deviation. In the future, the leader-employee pairing method can be selected to enhance the effectiveness and credibility of measurement data. (3) The mediating variables in this study only play a partial mediating role, indicating that there are other influencing factors on the influence process of humble 
leadership on employee creativity. In the future, other boundary conditions that influence humble leadership can be further explored.

\section{Reference}

[1] Zhou S J (2003). Transformational Leadership, Conservation, and Creativity: Evidence from Korea. The Academy of Management Journal. 46(6):703-714.

[2] Gong Y, Huang J C, Farh J L (2009). Employee Learning Orientation, Transformational Leadership, and Employee Creativity: The Mediating Role of Employee Creative Self-Efficacy. Academy of Management Journal. 52(4):765-778.

[3] Huang Qiufeng, Tang Ningyu (2016). A meta-analysis of the impact of transformational leadership and transactional leadership on employee innovation behavior. Soft Science. $30(3)$.

[4] Luo Linlian, Hua Changhua, Zhong Jing (2016). Research on the influence and mechanism of humble leadership on the creativity of knowledge workers: a mediated adjustment model -- based on the perspective of social cognition. R\&D Management. 28(4):106-116.

[5] Luo Yunna, Yang Gaosheng (2019). The influence mechanism of humble leadership on employee creativity. Science and Technology Management Research. (1): 156-161

[6] Wang Yanzi, Bai Ling, Luo Jinlian (2016). Research on the influence mechanism of humble leadership on the creativity of $\mathrm{r} \& \mathrm{~d}$ personnel. Foreign Economics \& Management. 38(10):76-88.

[7] Connelly C E, Zweig D, Webster J, et al (2012). Knowledge hiding in organizations. Journal of Organizational Behavior. 33(1):64-88.

[8] Kang S W (2014). Knowledge withholding: Psychological hindrance to the innovation diffusion within an organization. Knowledge Management Research \& Practice. 14(1): 144-149.

[9] Owens B P, Hekman D R (2012). Modeling How to Grow: An Inductive Examination of 
Humble Leader Behavior, Contingencies, and Outcomes. Academy of Management Journal. 55 (4): 787-818.

[10] Zhang X, Bartol K M (2010). Linking empowering employee creativity: The influence of psychological empowerment, intrinsic motivation, and creative process engagement. The Academy of Management Journal. 53(1): 107-128.

[11] Nielsen R, Marrone J A, Slay H S (2010). A New Look at Humility: Exploring the Humility Concept and Its Role in Socialized Charismatic Leadership. Journal of Leadership \& Organizational Studies. 17(1):33-43.

[12] Ford D P, Staples D S (2008). What is Knowledge Sharing from the Informer's Perspective. International Journal of Knowledge Management. 4(4): 1-20.

[13] He Yiming, Jiang Rongping (2014). Knowledge hiding behavior in organizations: reviews and perspectives. Human Resources Development of China. (13):49-55.

[14] Yuan Ling, Zhang Leilei, Tu Yanhong (2018). Research on the relationship between humble leadership and knowledge hiding curve. Soft Science. (11): 86-89.

[15] Cerne M, Nerstad C, Dysvik A, et al (2014). What Goes Around Comes Around: Knowledge Hiding, Perceived Motivational Climate, and Creativity. Academy of Management Journal. 57(1):172- 192.

[16] Dyne L V, Jehn K A, Cummings A (2002). Differential effects of strain on two forms of work performance: individual employee sales and creativity. Journal of Organizational Behavior. 23(1):57-74.

[17] Eisenberger R, Huntington R, Hutchison S, et al (1986). Perceived Organizational Support. Journal of Applied Psychology. 71(3):500-507.

[18] Kraimer M L, Wayne S J (2004). An Examination of Perceived Organizational Support as a Multidimensional Construct in the Context of an Expatriate Assignment. Journal of Management. 30(2):209-237. 
[19] Lu Jihua, Chen Lili, Zhao Xinan (2013). Research on the relationship between perceived organizational support, organizational commitment and knowledge worker engagement. Science of Science and Management of S.\& T. 34(1):147-153.

[20] He huitao, Ji Pengsheng, Yuan Zhiyong (2009). Research on the relationship between organizational support, employee knowledge sharing and sharing effectiveness. Science of Science and Management of S.\& T. 30 (11): 122-128.

[21] Owens B P, Johnson M D, Mitchell T R (2013). Expressed Humility in Organizations: Implications for Performance, Teams, and Leadership. Organization Science. 24(5):1517-1538.

[22] Zhou, J., \& George, J. M. (2001). When job dissatisfaction leads to creativity: Encouraging the expression of voice. Academy of Management Journal. 44(4), 682-696.

[23] Eisenberger R, Stinglhamber F, Vandenberghe C, et al (2002). Perceived supervisor support: Contributions to perceived organizational support and employee retention. Journal of Applied Psychology. 87(3):565-573.

[24] Baron R M, Kenny D A (1986). The moderator-mediator variable distinction in social psychological research: Conceptual, strategic and statistical considerations. Journal of Personality and Social Psychology. 51(6):1173-1182. 